\title{
SCRIPTORES Y NOTARIOS EN EL MONASTERIO DE FERREIRA DE PALLARÉS
}

\author{
por \\ JOSÉ ANGEL REY CAIINA
}

\section{S.IX-XII}

1. Scriptores eclesiásticos y laicos

La actividad notarial desarrollada en el monasterio de Ferreira de Pallares, así como toda la del reino astur-leonés, tiene sus orígenes jurídicos en la concepción del Derecho romano vulgar, tomando además de las Instituciones visigodas los tecnicismos documentales que al correr de los años evolucionan lentamente.

El scriptor, hasta la entronización de la dinastía navarra en Castilla con Fernando I, 1037, suele ser un clérigo que extiende los documentos como un simple experto sin que su nombre aparezca en los diplomas. Este hecho lo hallamos documentado frecuentemente en el cartulario monástico ${ }^{1}$. Perdura aún en esta área lucense la arcaica concepción visigótica que sostenía que la prueba documental era superior a cualquier otra que pudiese presentarse en un juicio. Sin embargo este fenómeno no es usual; lo normal

1 A.H.N.- 1239/2;1082/1,4,5; $132513 / 9 ; 1083 / 4,14 ; 1328$ A/18; 1085/12,15; $1086 / 12,16,22,1087 / 10$.

"CUADERNOS DE ESTUdiOS GALLEGOS", Tomo XXXIX, Fascículo 104, Santiago 1991. 
es que en los documentos aparezca una suscripción explícita de su autor, aunque sólo con su nombre ${ }^{2}$ : $\mathrm{N}$. qui notuit". Entre los redactores de los diplomas que figuran en este trabajo, los unos son clérigos, atestiguándolo así con el término "presbiter, clericus, diaconus qui notuit, scripsit, notauit, etc"3. Hay escribas que no añaden este vocablo a su antropónimo por lo que suponemos que son laicos ${ }^{4}$, dado que la cualidad de su estado podría dar mayor fiabilidad a su escritura.

La profesionalidad de estos escribanos se pone de manifiesto al aparecer su nombre en una serie de diplomas de datas sucesivas, lugares idénticos o cercanos y la misma terminología técnica de origen visigodo cuyo dominio era imposible para amanuenses ocasionales que carecían de formularios. Hasta $1107{ }^{5}$ se registra un "Petro qui notuit" que desarrolla su actividad en el Coto de Ferreira de Pallares. Sin embargo hasta $1164{ }^{6}$ el predominio de los clérigos sobre los laicos en el oficio de scriptor es de 14 a 1 en favor de los primeros. A partir de $1116^{7}$ los escribanos que actúan en la jurisdicción de Ferreira de Pallares, son legos, excepto los redactores de diplomas episcopales que se titulan "lucensis episcopi scriptor" 8 , "canonicus et notarius lucensis" 9 , "lucensis episcopi notarii et subdiaconi"10, y algún clérigo como "Fernandus Martini diaconus, scripsit" ${ }^{11}$, que en 1225 redacta una donación y cuya residencia suponemos en la ciudad episcopal de Lugo.

En el S.XII el estamento de los scriptores se desarrolla notablemente y aunque no consta documentalmente que estuviesen adscritos ya a una localidad determinada, su radiación puede colegirse sin embargo por la repetición de un mismo nombre, en documentos sucesivos, referente a lugares cercanos entre sí, pertenecientes además a la misma jurisdicción. Así "Petrus" aparece entre 1187 y 1227 extendiendo diplomas en los que las materias de las transacciones están ubicadas en diversas aldeas del Coto de Ferreira de Pallares ${ }^{12}$. Pero no ejerce un monopolio pues los mismos años conocemos otros escribanos actuando en los mismos límites ${ }^{13}$.

2 A.H.N.- $1082 / 2,3,6,7,9,10 ; 1325 \mathrm{~B} / 21 ; 1325 \mathrm{C} / 8$; etc.

${ }^{3}$ Vid. № 2.

4 A.H.N.- 1082/7,11,12,14,15,16,17, etc.

${ }^{5}$ A.H.N.- $1082 / 7$.

${ }^{6}$ A.H.N.- $1082 / 10$.

${ }^{7}$ A.H.N.- $1082 / 12$.

${ }^{8}$ A.H.N.- $1083 / 10$.

${ }^{9}$ A.H.N.- $1242 / 14$

${ }^{10}$ A.H.N.- $1084 / 8$.

${ }^{11}$ A.H.N.- $1083 / 15$

12 A.H.N.- $1082 / 15,17,21 ; 1083 / 2,5,22$.

13 A.H.N.- $1082 / 13,14 ; 1083 / 1,3,6,9,11$.

"CUADERNOS DE ESTUDIOS GALLEGOS", Tomo XXXIX, Fascículo 104, Santiago 1991. 
Algunos y entre ellos el citado "Petrus", tienen a sus órdenes un amanuense que se encarga de la confección material de la escritura y cuyo nombre figura a continuación del de su jefe: "Transcribente Pelagio Froile, acolitu"14.

\section{Scriptores monásticos}

Además de estos profesionales que operaban en los límites jurisdiccionales del Coto, los abades tuvieron sus escribanos propios reclutados y formados en el scriptorium abacial y que operaban en los asuntos internos del monasterio y en aquellos que hacían referencia a sus intereses económicos dentro del señorío abacial. Este hecho se registra a partir de $1129^{15}$, año en que el monasterio pallarense pasa de la condición de propio a la de autonomía administrativa con la consiguiente detentación de alta y baja jurisdicción, mero y mixto imperio. La primera referencia segura de esta actividad es de 1227 16; en dicho diploma aparece como escribano "qui notuit", Johannes Petri que sin identificarse positivamente como monje, aparece a lo largo de los años como redactor de los documentos más importantes para la economía monacal, compra-ventas, permutas, donaciones, después de la firma de otros religiosos de la abadía, llegando a titularse en 125717 "notarius Ferrarie". Su actividad se desarrolla desde 1227 hasta $1257^{18}$. A lo largo de este siglo otros tres monjes de Ferreira cumplen también este cometido: Fernandus Johannis, Pedro Eanes y Fernan Fernandes ${ }^{19}$ que atribuyéndose el apelativo de "monachus Ferrarie" y "monges de Ferreyra", refrendan las escrituras notariales "per mandado de abbade et conuento sobredito"20, o bien "teente as uizes en Pallares en lugar de Johan Martines, notario del rey.."21.

\section{S.XIII}

1. Notarii, notarii iurati y notarii concilii

Durante los primeros 62 años de esta centuria el estamento de los scriptores continúa elaborando los protocolos monásticos. La única va-

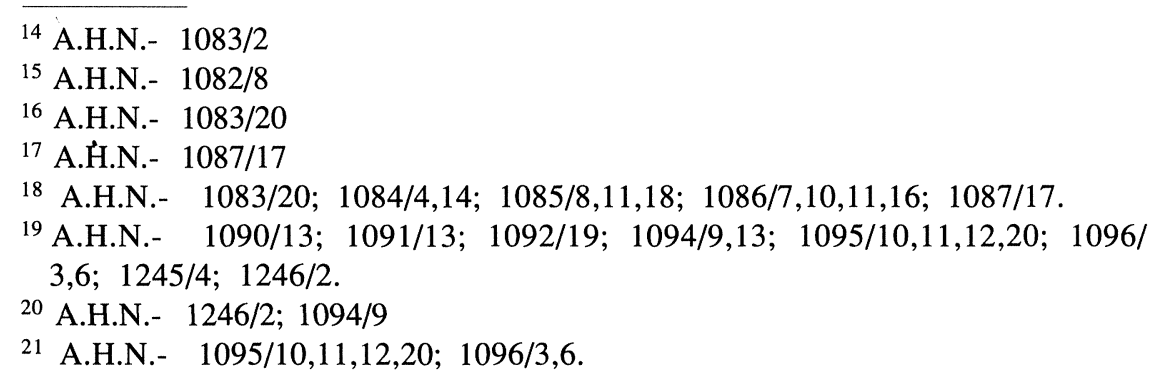

"CUADERNOS DE ESTUDIOS GALLEGOS", Tomo XXXIX, Fascículo 104, Santiago 1991. 
riante es la aparición del vocablo "notarius" aunque claramente aplicado a simples escribanos que a través de los "notarii episcopi' y de los apuntes de los clérigos llegados de las universidades de Italia, se aplicaron este apelativo para destacar su profesionalidad, tratando de alcanzar una mayor "fides publica". Así en $1217^{22}$ aparece "Romanus, lucensis notarius" redactando un documento en el Coto de Ferreira. Lo mismo hará en 122423 "Martinus, notariius", a quien conocemos desde $1219^{24}$ sin que se aplicase antes este título. Una característica de estos cuasi-notarios es su radicación que manifiestan después de su nombre al pie del documento "notarius $\mathrm{Pa}$ laris", "notarius Sarrie", "notarius en Monterroso", "notarius de Ulloa", etc. ${ }^{25}$. Su nuevo título les otorga un carácter público pero no oficial, indicando el lugar en que están avecindados, señal de una profesionalidad estable y sedentaria. En el período 1202-1216, además de los "notarii episcopi" a quienes nos referire0mos más adelante, hallamos trabajando para el monasterio y sus vasallos ${ }^{26}$ a los "notarii" Arias Munionis-Muniz, "notarius Asme, Dorre et Canbe"; Bartholomeus "notarius de Ulloa"; Dominicus Johannis, "notarius Sarrie"; Johannes de Sancto Jacobo, "notarius Pontis Miney"' Michael Fernandi, "notarius de Palaris", Romanus, "lucensis notarius".

Pero el notariado cobra importancia día a día con las nuevas ideas sobre el Derecho romano llegadas de Europa a través de los clérigos, estudiantes y peregrinos de Santiago. Algunos profesionales del citado estamento se denominan ya "notarius publicus"27. Entre 1246 y 1261 conocemos a Alfonsus Fernandi, "publicus notarius de Melide", 1248; domnus Adam, "publicus notarius de Monterroso", 1246; Matheus Petri, "notarius publicus de Orzilion", 1261.

Un paso más es la denominación de "iuratus" que se aplican desde 1253. En la colección diplomática de Ferreira de Pallares hallamos tres notarios que actúan con este título; Odoarius Johannis, "notarius compostellanus iuratus", 1253; Martinus, monachus, "iuratus notarius de Canba", 1269-1270; Suerius Pelagii, "notarius iuratus Ponte Ulie", $1260,{ }^{28}$.

Tanto los "notarii publici" como los "iurati", no tienen una "fides publica" de iure, sino que su autodenominación es un reflejo del cambio que

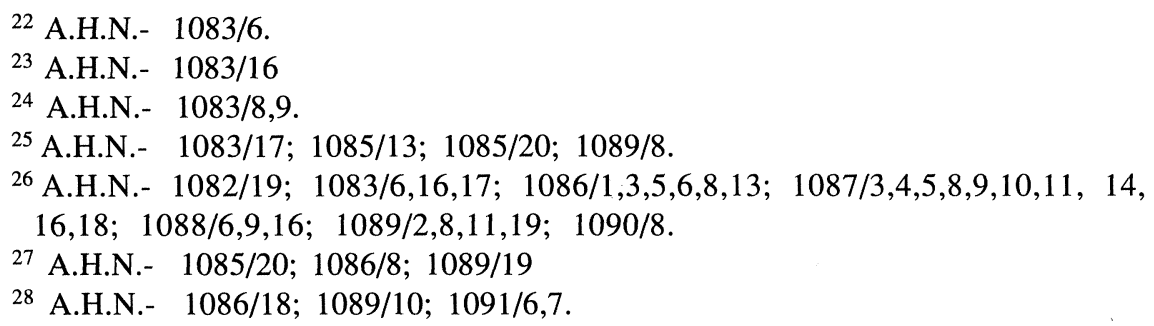

"CUADERNOS DE ESTUDIOS GALLEGOS", Tomo XXXIX, Fascículo 104, Santiago 1991 
se opera en Europa y en el reino. La España cristiana del S.XIII participa en el nuevo pensamiento jurídico europeo conocido como "Recepción". Intervienen en este fenómeno los juristas reales formados en las universidades italianas y del Sur de Francia, así como las élites Universitarias peninsulares que actúan en las curias episcopales e incluso algunos notarios progresistas $^{29}$.

También aparecen los "notarii concilii" que operan en los burgos de cierta importancia como Betanzos y Mellid ${ }^{30}$, entre 1257 y 1277. El Dr. Lucas Alvarez ${ }^{31}$ considera que no son sino scriptores que tratan de afianzar su status y que la palabra "concilii" no indica un nombramiento por parte del consejo sino una alusión a su residencia.

Tal hecho pudiera ser posible en el primer tercio de siglo pero en 1257 , año en que se sitúa el primer documento y en concejos tan importantes para la época como Mellid y Betanzos, la cosa ofrece dudas. Sabemos además que desde principios de siglo corrían ideas nuevas sobre el "officium de notariae" que indujeron a monarcas como Fernando III, 1217-1252, a reservar a la corona el derecho de creación de notarios en tierras de realengo ${ }^{32}$. Existían además otras fuentes de notariado como las curias episcopales y las comunales que por sus fueros tenían el privilegio respetado aún después de la Recepción, de crear sus propios notarios a quienes el nombramiento del Consejo concedía plena "fides publica". Según J.Bono ${ }^{33}$ los notarios de las ciudades y villas que por fuero eran nombrados comunalmente, sobre todo en la tradicionalista Galicia, no solían indicar en sus suscripciones el carácter de su creación, titulándose simplemente "N. notarius publicus de ..". Es nuesta opinión que los "notarii concilii" era de hecho y derecho funcionarios públicos que autorizaban legalmente, en virtud de su nombramiento concejil, los documentos expedidos en su despacho.

\section{Scriptores y notarii episcopi}

Los abades de Ferreira de Pallares, en su calidad de prelados mayores, ejecutan frecuentes transacciones tanto con los ordinarios de Lugo como con los jerarcas de otras Órdenes religiosas de la diócesis y aún de toda

\footnotetext{
${ }^{29}$ Lacarra. Sobre la recepción del Derecho Romano en Navarra. AHDE. 11,457 y 55.

30 A.H.N.- 1087/19; 1092/15,18; 1093/6,13,14.

31 Actas de las I jornadas de Metodología aplicada de las Ciencias Históricas. "Documentos notariales y notarios del monasterio de Osera". Págs. 223 y ss. 1975.

32 Bono, J. "Historia del Derecho Notarial Español" T. II, págs. 111 y ss. Madrid, 1979.

${ }^{33}$ Bono, J. Obra cit. T. II, págs. 143 y ss.
} 
Galicia. En estos menesteres suele actuar el notario del eclesiástico de mayor categoría o uno residente en los términos de su jurisdicción.

En la ciudad de Lugo desarrollaban la función notarial clérigos de la canónica que similares a los scriptores antedichos, tanto escrituraban para el obispo y cabildo como para los particulares, fuesen clérigos o laicos. Además de estos simples amanuenses ${ }^{34}$, aparecen, desde 1225, autentificando documentos del fondo de Ferreira de Pallares "notarii lucensis" así en los asuntos entre los prelados de Lugo y Ferreira como entre seglares $^{35}$. Se titulan "notarius lucensis" y "notarius ecclesie lucensis" indistintamente, lo que nos hace suponer que no había una clara distinción entre sus deberes para con la curia y los particulares. Consideramos a estos notarios episcopales de la primera mitad del siglo XIII diferentes de los "notarii publici", que los prelados lucenses nombraban para la ciudad de su sede en virtud de sus atribuciones señoriales y privilegios reales ${ }^{36}$.

\section{Otras formas de autentificación durante el S.XIII}

Durante esta centuria y aún en las dos siguientes, tanto los abades de Ferreira de Pallares como sus súbditos y bienhechores utilizan otros medios para legalizar sus documentos: cartas partidas, escrituras autorizadas por la "fides" de los testigos, por el sello de los otogantes y algunas veces por la autoridad propia del documento.

La carta partida es un sistema introducido para asegurar la autenticidad de los protocolos por vía complementaria de los testigos y del notarioescriba $^{37}$. No hubo en esta parte de la actual provincia de Lugo una reacción contra el valor probatorio de los diplomas, pero para reforzar su autenticidad se usan las "cartae divisae", cartas partidas, cuya difusión en el reino castellano-leonés es tardía, S.XII ${ }^{38}$. Las hallamos utilizadas en los negocios bilaterales, compra-ventas, permutas, foros, donaciones, etc. $\mathrm{Su}$ denominación técnica "chirographum", aparece raramente en los pergami$\operatorname{nos}^{39}$; las divisas son las letras del alfabeto ${ }^{40}$. Las cartas así denominadas

${ }^{34}$ A.H.N.- $1083 / 10,18 ; 1084 / 3$.

35 A.H.N.- 1084/8,19; 1085/14,16; 1086/15,17; 1087/6,7; 1088/13; 1091/19; $1092 / 4,5 ; 1242 / 14 ; 1245 / 5 ; 1328 \mathrm{~A} / 18 ; 1329 \mathrm{~A} / 7$.

${ }^{36}$ Bono, J. Obra cit. T. II, págs. 193-194.

${ }^{37}$ Lucas Alvarez. Obra cit. pág. 224.

${ }^{38}$ Bono, J. Obra cit. T. I, págs. 152 y ss.

39 A.H.N.- 1082/19; 1088/17; 1089/15,16; 1091/3.

40 A.H.N.- $1082 / 19 ; 1083 / 10,13,23 ; 1084 / 1,3,7,10,14,17 ; 1085 / 1,8,9,16,22$; $1086 / 7$; $1090 / 5,6,13,19 ; 1091 / 1,3,7,8,21 ; 1092 / 3,19 ; 1094 / 3,9,15 ; 1095 / 6$; $1097 / 13 ; 1098 / 9,7 ; 1099 / 5,7,8,10,14,19 ; 1100 / 8 ; 1101 / 20 ; 1102 / 3,20 ; 1243 /$ $19 ; 1245 / 4 ; 1252 / 14 ; 1253 / 3 ; 1255 / 11 ; 1256 / 5 ; 1257 / 8,19 ; 1259 / 8$.

"CUADERNOS DE ESTUDIOS GALLEGOS", Tomo XXXIX, Fascículo 104, Santiago 1991. 
no pueden ser consideradas aisladamente en la Colección Diplomática de Ferreira de Pallares, pues aunque participan de las condiciones de la bilateralidad y suma importancia económica de su contenido, sólo dos documentos $^{41}$ están garantizados por este último procedimiento. Todos los demás añaden a su valor probatorio el sello de los otorgantes ${ }^{42}$; el sello y los testigos ${ }^{43}$; el sello, los testigos y el regnante ${ }^{44}$ el sello, los testigos y el scriptor ${ }^{45}$; el sello, los testigos y el notario ${ }^{46}$; el sello y la firma del notario ${ }^{47}$; el sello y la firma del scriptor ${ }^{48}$; notario y testigos ${ }^{49}$ scriptor y testigos ${ }^{50}$; scriptor, testigos y regnante ${ }^{51}$ Lo cual quiere decir que en esta área gallega la carta partida, per se, no llega a alcanzar plena vigencia en ningún momento y sólo se utiliza para dar mayor fiabilidad al documento que ya contiene la "fides publica" por uno o varios elementos de los que acabamos de enumerar, siendo los más importantes, scriptor, notario, testigos y sello.

Continúa además en la documentación de Ferreira de Pallares el ya visto concepto visigodo de la fuerza probatoria del propio documento, considerada como de absoluta garantía. Así en el S.XIII hallamos 12 pergaminos $^{52}$; en los que se cumple este enunciado. Cinco son bilaterales ${ }^{53}$, donación, venta, pacto, pleito y carta de dote; de los otros siete ${ }^{54}, 5$ son apeos y 2 testamentos.

Otros pergaminos además de la "fides" sobredicha, cuentan con la de los testigos ${ }^{55}$.

Otra modalidad de asegurar la fuerza probatoria es el sello "pendente", propio de los señores eclesiásticos y laicos además de los concejos ${ }^{56}$, cuyo

41 A.H.N.- 1098/9; $1257 / 8$.

42 A.H.N.- 1099/10,14.

43 A.H.N.- 1091/1;1098/17; 1099/5,7;1101/20;1102/3; 1255/11; 126/5; $1257 / 19$.

${ }^{44}$ A.H.N.- $1085 / 1$.

${ }^{45}$ A.H.N.- $1084 / 3$.

46 A.H.N.- 1095/3; 1097/13.

47 A.H.N.- 1091/3; 1100/8.

48 A.H.N.- $1252 / 14$.

49 A.H.N.- 1085/16;1088/17; 1089/15,16; 1091/21; 1094/1; 1095/6; 1099/19; $1101 / 18 ; 1102 / 20 ; 1252 / 20 ; 1253 / 3 ; 1259 / 8$.

50 A.H.N.- $1082 / 19 ; 1083 / 10,23 ; 1086 / 17 ; 1087 / 8 ; 1090 / 6,19 ; 1091 / 7,8 ; 1092 /$ 3,$19 ; 1094 / 9 ; 1243 / 19 ; 1245 / 4$.

51 A.H.N.- $1083 / 13 ; 1084 / 7,10,14,17 ; 1085 / 8,22 ; 1086 / 7$.

52 A.H.N.- $1085 / 12,15 ; 1086 / 12,16$; y nota 51.

53 A.H.N.- 1085/12;1086/12,16; 1088/7; 1096/11.

54 A.H.N.- $1086 / 12 ; 1090 / 15 ; 1096 / 12,14,15 ; 1103 / 19$.

55 A.H.N.- 1082/4; 1083/4,14; 1089/18; 1091/22; 1094/13; 1096/12.

56 Bono J. Obra cit. T. I, págs. 152-153. 
uso comienza, como las cartas partidas, en el S.XII. En estos protocolos aparecen a veces testigos ${ }^{57}$, a veces no $^{58}$.

\section{Renovación del notariado y del documento en la segunda mitad del siglo XIII}

A partir de 1260 se consagra un nuevo esquema tanto en los protocolos como en sus redactores.

Los viejos scriptores continúan actuando en el monasterio aunque su actividad se reduce a documentos propios de la abadía y suelen titularse: "N. monachus de Ferraria"59.

\section{La recepción: Orígenes}

El renacimiento del Derechó se inicia en Bolonia a finales del S.XI con la recensión de la obra de Justiniano y con las Decretales de los Sumos Pontífices. Esta ideología justinianea sustituye paulatinamente al viejo ideario teodosiano-alariciano que había predominado en las naciones de origen latino. Tal pensamiento transformará el status del scriptor o escriba del que nacerá el notario público cuya función será conferir autenticidad legal al documento al implantar el "instrumentum publicum" o diploma fehaciente per $\mathrm{se}^{60}$. La doctrina en que se basa la nueva concepción del notario, es la promulgada por Alejandro III hacia 1167 en su Decretal "Scripta authentica", basada en los glosadores y en la canonística, afirmando que no tendrán valor público los documentos no ejecutados "per manum publicam", ni dotados de sello auténtico, habiendo fallecido los testigos que en ellos hubieren intervenido.

\section{La recepción en la España cristiana}

La España cristiana del S.XIII participa del nuevo pensamiento jurídico europeo en un proceso conocido como "recepción". Intervienen en este fenómeno los juristas reales y los académicos formados en las universidades de Italia y del S. de Francia, así como las élites universitarias que actúan en las curias episcopales e incluso algunos notarios ${ }^{61}$. Esta re-

\footnotetext{
57 A.H.N.- 1085/1; 1091/1; $1097 / 17$.

58 A.H.N.- 1089/14; 1094/1; 1247/20; 1248/15.

59 A.H.N.- 1091/13,24; 1092/19; 1094/9; 1095/10,12;1096/6; 1245/4; 1246/2.

${ }^{60}$ Bono J. Obra cit T. I, pág. 165.

${ }^{61}$ Lacarra. Sobre la Recepción del Derecho Romano en Navarra. AHDE, 11, 475 y ss. García, A. Ibid, 46, 315-43; 36, 575-92.
} 
novación no excluyó el Derecho nacional de cada reino sino que se produjo una simbiosis del "ius propium" y del "ius commune". De ahí que a partir de ahora la legalidad será "segund fuero e derecho". La "recepción" consagró en Castilla la transformación del scriptor en "notarius publicus" y la del documento en "instrumentum publicum", durante el reinado de Alfonso X el Sabio, 1252-1284. La fase de introducción se lleva a cabo mediante el Fuero Real y la de difusión por el Espéculo y las Partidas ${ }^{62}$. El Fuero Real, primero Fuero del Libro, ya compuesto en $1255^{63}$, es una hábil composición calcada sobre el Liber Judiciorum según las doctrinas romano-canónicas, con escasas concesiones al Derecho consuetudinario castellano-leonés, para intentar conseguir una unidad de las leyes del reino.

El Espéculo, ya redactado en $1260^{64}$, fue un libro legal para uso de los jueces de la corte real y de los territoriales y locales de nombramiento regio; contenía la ley del rey, distinta de los fueros de las ciudades.

El libro de las Leyes es una reelaboración del Espéculo llevada a cabo entre 1270 y 1280, completada en el reinado de Fernando IV el Emplazado y dominada "Siete Partidas". Tiene un carácter doctrinal, destinado al uso de los juristas y universitarios.

Fuero Real y Partidas constituyen verdaderas ordenaciones notariales al establecer una normativa en la institución y en el documento público. Hay además otras fuentes locales: los privilegios reales que reconocen e derecho de las ciudades y señores a nombrar notarios y las reglamentaciones municipales sobre estos funcionarios.

\section{Notariado real, $1262-1346$}

La lectura de los documentos de Ferreira de Pallares nos lleva a la conclusión de que a partir de 1262 aparecen en aquella región los primeros notarios de nombramiento regio. El pergamino 1089/22 del A.H.N. aparece firmado por "Martin Pedrez, notario del rey publico en Goyos et en Nalar" y signado con su sello. Desde luego no hallamos prueba alguna de tal nombramiento, pero los datos documentales contenidos en los protocolos autorizan este aserto. Además el Fuero real está ya redactado en $1260^{65}$ y se manda allí que en todas las ciudades y villas mayores sean puestos escribanos públicos que sean jurados y puestos por el rey o por quien él mandase, para que escriban los contratos y pleitos que los hom-

62 García Gallo. El libro de las Leyes de Alfonso el Sabio. Del Esp. a las Partidas, AHDE, 21-22, 344-528.

${ }^{63}$ Bono J. Obra cit T. I, pág. 236.

${ }^{64}$ García Gallo. AHDE, 21-22, 386-90 y 46, 629, nº 53.

65 Vid. notas $62,63,64$. 
bres hacen entre sí ${ }^{66}$. A partir de ahora tales funcionarios aparecen en las distintas jurisdicciones en que se mueven los intereses del monasterio: "Michael Fernandi, notarius iuratus domni regis", figura como notario de Pallares y Portomarín entre los años 1264 y $1291{ }^{67}$. Al lado de su nombre aparece generalmente su sello, aunque en algunos documentos no se cumple este mandato real ${ }^{68}$. En la jurisdicción de Pallares, entonces de realengo, aparece también Johan Perez, "notario jurado del rey en terra de Pallares", entre los años 1297 y $1304^{69}$. En Orcellón, Orense, se nos presenta "Domingo Rodizit, notario del rey en Orzelon" en 1264, "Johan Fernandez, en Orzellon et en Buual et en Castella et en no Bolo de Senda" en 1271, "Pedro Martinez" en 1274 y "Joanh Ares" en 127670. "Ruy Guilielmiz"se titula en 1268 "notario del rey en Sarria"71. "Lourenzo Fernandez" lo hace "na pobla de Palas de Rey" en 1272 ${ }^{72}$. "Affonso Eanes" en Castroverde en 127773. "Fernan Martinez, Alfonso Martinez y Johan Martinez" en Outeyro de Rey en 1285, 1290 y 1292 respectivamente ${ }^{74}$. En Portozolo hallamos a "Fernan Gyllen" en 128775; y "Aras Perez" firma como tal en "Repostaria et en Reuoredo" en 129476. Algunos de ellos como Michael Fernandi, Fernan Martinez y Johan Martinez tienen a sus órdenes un amanuense cuya obra legalizan con su firma y sello.

\section{Notarios suplentes}

No se estimaba un deber propio el desempeño directo de la función notarial. En todas partes se consideraba válida y normal la delegación "ad vicem" que confería el titular a otra persona ${ }^{77}$, a menudo notario también, denominado "escusador", pero no siempre como veremos enseguida. Podía un mismo personaje obtener del favor real varias prebendas de esta especie por un número determinado de años, por vida o a perpetuidad, que él luego arrendaba, o bien en los lugares apartados de su jurisdicción nombraba un notario "escusador" si tenía título, o un simple delegado, si

${ }^{66}$ Fuero Real, 1, 8, 1.

67 A.H.N.- $1091 / 8,10,23 ; 1092 / 2,7,9,11,12,13,16,17 ; 1093 / 1,2,3,4,11,12,18$, 19,$20 ; 1094 / 5,8,10,11,12,15,19 ; 1095 / 1,2,4,9,14 ; 1244 / 10 ; 1246 / 5$.

68 A.H.N.- 1091/23; 1092/2,7.

69 A.H.N.- 1096/7,9; 1097/14; 1249/7.

70 A.H.N.- 1090/7; 1091/11; 1092/14; 1093/10.

71 A.H.N.- $1091 / 21$.

72 A.H.N.- 1091/20.

73 A.H.N.- 1093/15.

${ }^{74}$ A.H.N.- 1094/18; 1095/8,18.

75 A.H.N.- $1095 / 5$.

76 A.H.N.- 1096/2,4.

${ }^{77}$ Bono J. Obra cit. T. II, págs. 322-25. 
no lo tenía, que ejercía sus funciones y usaba su sello, generalmente similar al de su patrón. La sustitución afectaba solamente a la función y así los que la ejercían se autodenominaban "teente as unizes en Pallares en lugar de ..."78, "per mandato de Arie Munionis, notarii de Monterroso" 79, "notario de Portomarin en lugar de Nicollaao Johannis" ${ }^{80}$. La corruptela tanto del pluriarriendo real como de la cesión particular fue denunciada en las Cortes de Valladolid de 1307 y Fernando IV llegó a prohibirlo pero sin conseguir nada ${ }^{81}$. Esta costumbre fue normal en los ámbitos económicos y espirituales del monasterio de Ferreira de Pallares. Los suplentes allí operantes se titulan a veces notarios "Affonso Peres, notario en lugar de Diego Dias, notario publico del rey en Monterroso" ${ }^{82}$, pero con mayor frecuencia aparecen como simples scriptores "Rodericus Garsie, loco Laurentii Fernandi, notarii domni regis in Pallares" 83, "Diego Martinez, escriui esta carta per mandado de Lourénzo Fernandez, notario jurado del rey na pobra de Palaz de Rey"84, "Johan Perez, monges de Ferreyra, et teente as uizes en Pallares en lugar de Johan Dominguez, notario del rey na hoor de Monterroso ${ }^{85}$.

Estos suplentes son anárquicos en el uso del sello. Unos lo usan ${ }^{86} \mathrm{en}$ todos los documentos que de ellos conocemos, otros en ninguno ${ }^{87} \mathrm{y}$ con frecuencia lo ponen en unos y en otros $\mathrm{no}^{88}$; algunos se lo atribuyen "et pogi meo signo", "et puge y meo signo"89, otros dicen que es copia del que estampa el notario oficial "et fis y meo signo, semelante o de Juan Perez, notario sobredito" 90 . Pero no sólo autorizan documentos en este período los notarios reales y sus suplentes, con mayor frecuencia lo hacen los viejos scriptores como el monje de Ferreira, Fernandus Johannis, que desde 1263 a 1282 redacta 18 protocolos $^{91}$, y lo mismo hacen Pedro Johannis, "peuedro de choro de Lugo"92, Diego Martínez, Nuno

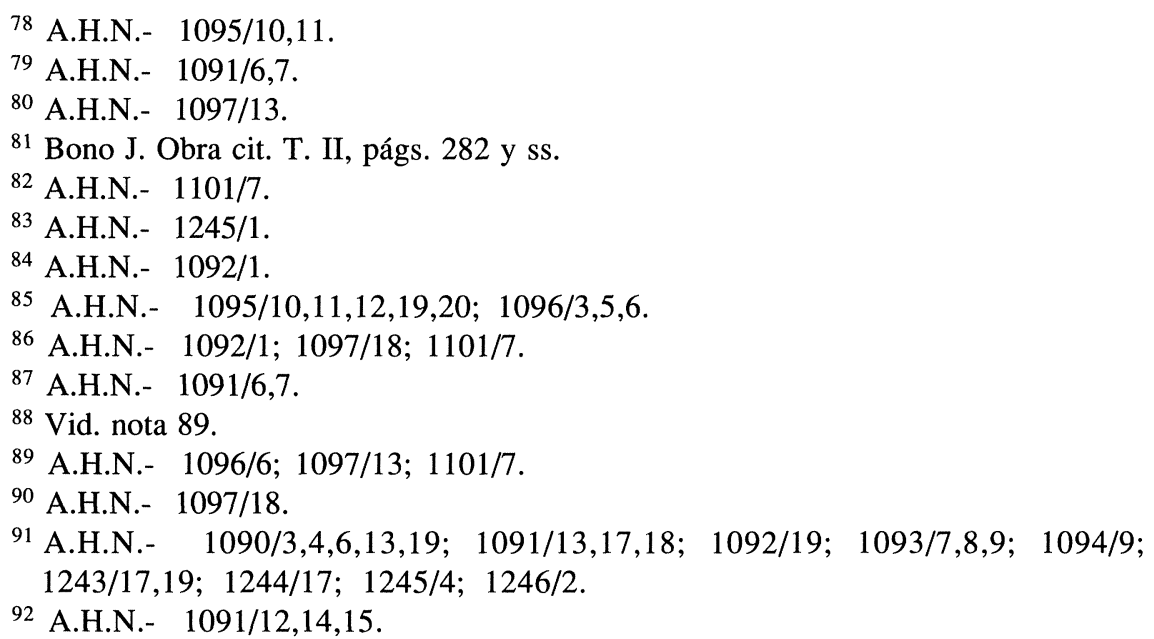

"CUADERNOS DE ESTUDIOS GALLEGOS", Tomo XXXIX, Fascículo 104, Santiago 1991. 
Johannis y Johan Perez ${ }^{93}$. También los notarios de la curia lucense, además de trabajar en el terreno eclesiástico, ejercen su oficio en favor de los particulares, máxime con los de su estamento. En la ciudad de Lugo, episcopal y señorial, había dos clases de notarios, los de la curia y los de la ciudad, ambos nombrados por su común señor, el obispo, superior jerárquico para los clérigos y jurisdiccional para los laicos.

Entre 1262 y 1346 hallamos la impronta de ambas clases de notarios en los pergaminos pallarenses. Los escribanos de la curia y cancillería se titulan "lucensis notarius" 94 y son canónigos de la catedral. Los notarios públicos son también nombrados por el prelado, basándose en el señorío que ejerce sobre la ciudad y su alfoz ${ }^{95}$, cuyo poder le es confirmado en 1295 por el rey ${ }^{96}$. Se titulan, hasta principios del S.XIV, "publicus notarius lucensis" y "notarios publicos de Lugo"97.

También actúan los notarios comunales nombrados por el concejo en que están radicados y autorizados para su labor dentro de los límites concejiles $^{98}$. Las ciudades y villas comenzaron ya antes del reinado del rey Sabio a desingar sus propios escribanos, usando su autonomía local garantizada por sus fueros y éstos se titulan "notarius publicus de N." 99 . En la documentación que hemos estudiado hallamos un ejemplo de este estamento en la persona de Petrus Dominici que se proclama "notarius Milide puplicus et iuratus" y "notario jurado do conçelo de Milide", abarcando su obra desde 1264 hasta $1277^{100}$.

Continúa además garantizándose la validez documental por otros sistemas ya estudiados: cartas partidas ${ }^{101}$; protocolos con el sello de cera colgado, otorgados por el abad y otras dignidades eclesiásticas ${ }^{102}$; otros avalados solamente por los testigos ${ }^{103}$; y algunos cuya única autoridad es la prueba documental ${ }^{104}$.

\footnotetext{
93 A.H.N.- 1092/3,6; 1095/3.

${ }^{94}$ A.H.N.- $1090 / 11,14,16 ; 1091 / 19 ; 1092 / 4,5 ; 1095 / 6,17 ; 1097 / 19 ; 1130$ D/9; $1243 / 21$.

${ }^{95}$ Bono J. Obra cit. T. II, págs. 111 y ss.

${ }^{96}$ Ferro Couselo, J. A. "A vida dos devanceiros. Escolma de documentos en Gallego dos s. XIII ao 16". 1-2. 1976.

97 A.H.N.- 1094/6;1096/1; 1097/2;1251/11;1284/3.

98 A.H.N.- $1090 / 8$.

99 Bono J. Obra cit. T. II, pág. 111.

100 A.H.N.- 1090/8,17,18; 1091/16;1093/14,15,18; 1093/6,13,14.

101 A.H.N.- 1091/1; 1096/19.

102 A.H.N.- 1091/21;1093/21; 1094/17; 1096/17; 1097/11,20;1101/11; 1102/ $18 ; 1247 / 20 ; 1248 / 15 ; 1255 / 11$.

103 A.H.N.- $1094 / 2,13 ; 1096 / 12,14,15 ; 1097 / 4,7,8$.

104 A.H.N.- 1090/15;1091/22; 1096/11,12,20,21; 1097/9,10.
} 


\section{Notarios señoriales}

También a comienzos del S.XIV aparecen los notarios señoriales que alcanzarán gran importancia en esta centuria. Así en 1301 Johan Dominguez y en 1314 Fernando Perez se autodenominan "notario publico dado pelo bispo de Lugo ao conçello desse mismo lugar"105; aquí el caso no es nuevo pues los prelados lucenses ya los nombraban tiempo atrás, lo que resalta es la confirmación real de tal poder. Pero el obispo de Lugo también nombraba escribanos en sus señoríos fuera de la ciudad de Lugo y su alfoz y así hallamos en el antiguo condado de Pallares, ahora tierra de abadengo, a Fernan Fernandes "notario público dado pello bispo de Lugo en terra de Pallares et no couto de Ferreyra"106. Debemos aclarar que su titularidad en el referido Coto no le había sido otorgada por el prelado lucense que no poseía jurisdicción temporal en dicho término sino que el abad y más tarde los señores de otros Cotos limítrofes, la acumulaban en el escribano más importante de los cercanos, aprovechando las concesiones reales que les otorgaban los privilegios de nombrar notarios en sus señoríos.

\section{6-1514}

En este período final de la existencia de la abadía de Ferreira de Pallares pierden vigencia las cartas partidas, los documentos avalados por el sello, excepto los procedentes de la corte papal y episcopal y hasta los notarios de designación regia, ocupando su lugar los señoriales, debido a que las tierras que rodean el Coto monástico son señoríos eclesiásticos y laicos que tienen la prerrogativa de nombrar sus propios funcionarios.

Hay un sólo protocolo avalado por el sello del otorgante ${ }^{107}$, el juez de Monterroso, Nuño Fernández, en 1352; emanados de la curia lucense hallamos tres ${ }^{108}$, autorizados por el sello del otorgante, obispo y archidiácono de Gomelle respectivamente, y por la firma.

La simple carta partida desaparece aunque se conservan algunas en que a la prueba fiduciaria concedida a tales instrumentos, se le añade el sello del otorgante ${ }^{109}$, o bien el sello y la presencia notarial ${ }^{110}$. Unos y otros son foros concedidos por los abades de Ferreira.

\footnotetext{
105 A.H.N.- 1097/12,17; 1101/3.

106 A.H.N.- $1101 / 8,9,10,12,13,14,17,19 ; 1255 / 7$.

107 A.H.N.- $1102 / 7$.

108 A.H.N.- 1102/2,18; 1103/14.

109 A.H.N.- $1102 / 3 ; 1257 / 19$.

110 A.H.N.- $1256 / 5 ; 1101 / 20 ; 1102 / 20$.
} 


\section{Notariado real}

La enseñanza de esta moderna disciplina no era impartida en las universidades, ni españolas ni extranjeras, se llevaba a cabo en los despachos de notarios particulares sin exigencia de estudios universitarios. Sabemos que en Cataluña cualquier notario podía tener escuela para enseñar su "sciencia" 111 . En Castilla no se exigía práctica para superar el examen 112 .

Los notarios reales se dividían en dos clases: notarios públicos del rey o de número, encardinados en una ciudad, o villa determinada; y escribanos del rey, con competencia en todo el reino pero sin ubicación definitiva cuyo título los facultaba para su función mientras no interfirieran la competencia de los oficiales o de número ${ }^{113}$.

Entre los primeros sólo hallamos en este período a "Pedro Fernandez" 114 "notario pubrico por el rey en Chantada et em seu allffos" en 1349.

Los segundos son más numerosos y ejercen su labor en los distintos señoríos, eclesiásticos y laicos que rodean al monasterio pallarense: Portomarín, Lugo, Pallares, Monterroso, Palas de Rey, etc. El título que usan unánimemente es: "notario" o "escripuano publico del rey noso sennor et seu notario publico en na sua corte et en todos los seus reynos et sennorios"115, sin que figure su adscripción a ningún Coto, ciudad o villa, aunque alguno de ellos ${ }^{116}$ como Jácome Rodríguez de Pedraça, consigue ubicarse numeriamente en una jurisdicción determinada mediante el nombramiento señorial, en este caso Monterroso, Coto del conde de Monterrey.

\section{Notariado señorial}

Los señores jurisdiccionales gallegos, clérigos y laicos, así como los concejos consiguen desde los tiempos de Fernando III la prerrogativa de nombrar el funcionariado notarial en sus $\operatorname{Cotos}^{117}$. Así desde mediados del S.XIV los notarios con que operan los abades del monasterio de Ferreira, son los que ejercen bien en sus señoríos, Ferreira de Pallares, Mourulle y Aldea, bien en los de sus vecinos más o menos cercanos: Repostería, Chantada, Monterroso, Lugo, Pallares, Portomarín, Recelle,

${ }^{111}$ Código de las Costumbres de Tortosa, en B. Oliver, 4,9,9,5.

112 Bono J. Obra cit. T. II, págs. 226 y ss.

113 Bono J. Obra cit. T. II, págs. 226 y ss.

114 A.H.N.- $1102 / 6$.

115 A.H.N.- 1103/21; 1105/14,16; 1265/9; 1281/17; 1300/5.

115 A.H.N.- $1105 / 15$.

117 Vid. nota 112.

"CUADERNOS DE ESTUDIOS GALLEGOS", Tomo XXXIX, Fascículo 104, Santiago 1991. 
Sanfiz do Hermo, Servián, Quiroga, además de sus suplentes y de los notarios apostólicos de los que hablaremos luego.

Entre 1346 y 1514 hallamos representados en la documentación estudiada a los siguientes notarios señoriales en los Cotos correspondientes: Afonso Fernandes, 1436-37,118. Aluaro Gomes de Constante, 1457, (119), Diego Gomes das Camoiras, 1478-92, ,20, Fernan Garçia, 135994, ${ }^{121}$, Gonçaluo Peres, 1390-91, ${ }^{122}$, Johan Fernandes, 1417, ${ }^{123}$ Johan Vasques de Peraredo, 1449-79, ${ }^{124}$, Vaasco Gil, 1413-46, ${ }^{125}$, notarios públicos de Lugo "por autoridade do bispo dese lugar"; Fernan Fernandes, 1346-54, ${ }^{126}$, Gonçaluo Peres, $1349-69,{ }^{127}$ Vasco Rodrigues, $1428,{ }^{128}$; notarios "dado pollo bispo de Lugo en terra de Pallares et no couto de Ferreyra"; Afonso Peres, 1355, ${ }^{127}$, Aras Afonso, 1391-93, (129), Afonso Martines, 1382-84, ${ }^{130}$, Gonçaluo Eanes de Lis, 1457-58, 131, "notario puprico en na marynda de Monterroso polo sennor conde don Pedro"; Afonso Fernandes de Portomarin, 1411, ${ }^{132}$, Diego Affonso, 1389, ${ }^{133}$, Gomes Yanes de Costante, 1438, ${ }^{134}$. Pedro Vasques de Lor, 1440, ${ }^{135}$, "notario publico en na vila de Portomarin por la Ordeen de San Juan"; Johan Affonso, 1382, ${ }^{136}$, "notario publico por nostro sennor el duque de Uilla Franca çerca Valcarçel.

\section{Notarios excusados}

Además de los titulares, continúan trabajando los notarios suplentes, aunque su número disminuye. Algunos de ellos consiguen obtener la

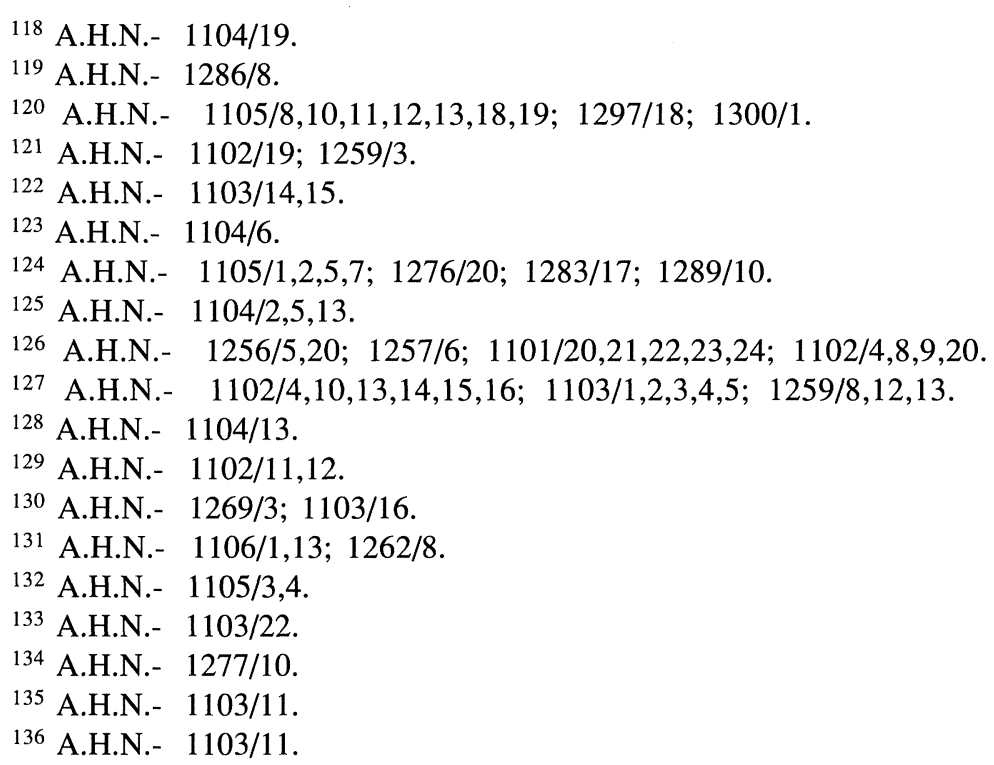


plaza de numerario. Así Aluaro Rodrigues comienza autodenominándose "notario excusado en nos coutos de Ferreyra et dos outros coutos cercanos do dito moesteyro por Johan Rodriges Furtio, notario publico en na meyrindade de Monterroso"137, para luego presentarse como "notario publico do moesteyro de Ferreyra et de seus coutos et lugares et notario escusador en nos coutos de Santa Ougea et de San Fiis et de Reçelle por Johan Rodrigues Furtio..."138. El hecho supone que Alvaro Rodríguez no es un simple amanuense sino un profesional titulado como también el interés de los abades de Ferreira de Pallares de desvincularse de personas sometidas a otras jurisdicciones como era el notario de Monterroso nombrado por el conde de Monterrey para sus señoríos próximos a la abadía. También en 1412 se nos presenta Fernan Peres, "notario scusador en terra de Tauoada por Gomes Peres, notario publico de Chantada et seu alfos"139. La razón de la suplencia, en este caso, es la lejanía de los lugares y la dificultad de los desplazamientos.

\section{Notarios apostólicos}

A partir de 1416 aparece un nuevo elemento entre el notariado que trabaja para el monasterio de Ferreira de Pallares: los notarios apostólicos. Eran creados sin adscripción local por el papa y más frecuentemente por los delegados y ordinarios de lugar, mediante bula papal concedida por previa solicitud, súplica. Son clérigos y naturales del reino y a veces aducen acumulativamente el título de creación real o señorial ${ }^{140}$. Su competencia era de territorialidad ilimitada pero al incardinarse en una determinada diócesis, necesitaban la aprobación episcopal, a no ser que hubiesen sido creados por el propio obispo por concesión papal. No fueron bien acogidos por sus colegas de nombramiento regio y ya en las Cortes de Toro de 1371 se pidió al rey que les fuese prohibido redactar documentos no privativos de la iglesia, a lo que accedió el monarca, a no ser que lo hiciesen con autoridad real, sin que tal disposición tuviese resultado positivo alguno ${ }^{141}$.

En la documentación aquí estudiada vemos entre 1416 y 1514, a una decena de eclesiásticos que desempeñan esta función: Ares Lopes de Seuil, Johannes Ferdinandi, Juan de Cardoso, Vasco de Prado, Gil Peres de Saa, Gonçaluo Diaz de Freyxon, Cristoual de Cordoba, Juan Luoren-

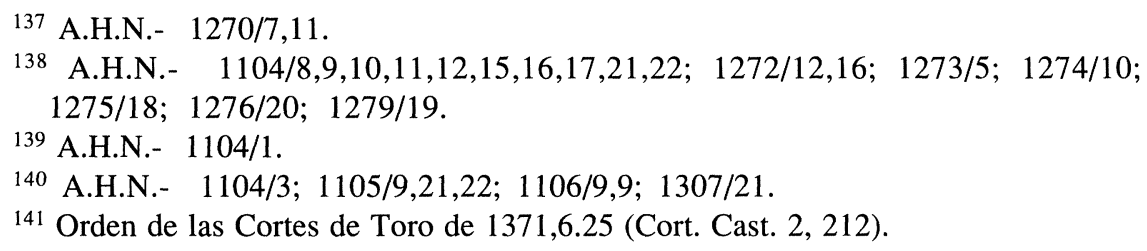


ço y Gomes Aluares ${ }^{142}$. Todos ellos se titulan "notario apostolico por la abtoridad apostolica", añadiendo algunos, como ya hemos dicho antes, la aprobación episcopal, real o señorial.

\section{Conclusiones}

1. Predominio absoluto del elemento clerical entre los scriptores o amanuenses hasta 1116 en que los laicos los desplazan a las curias episcopales.

2. Profesionalización y radicación del estamento de los escribanos en el S.XII.

3.A lo largo del S.XIII aparecen sucesivamente los "notarii", "notarii iurati" y los "notarii concilii", los dos primeros sin nombramiento ni autoridad legal, los últimos, hacia mediados de siglo, con plena "fides publica" otorgada por los concejos.

4. Desde 1262 se desarrolla el notariado real, resultado de una nueva concepción del Derecho (Recepción).

5. A partir de 1346 predominio de los notarios señoriales que desbancan en los diversos Cotos a los de designación real, apareciendo también los notarios apostólicos.

142 A.H.N.- $1104 / 3,14 ; 1105 / 9,20,21,22 ; 1106 / 5,6,9,10 ; 1304 / 12 ; 1307 / 21$.

"CUADERNOS DE ESTUDIOS GALLEGOS", Tomo XXXIX, Fascículo 104, Santiago 1991. 